
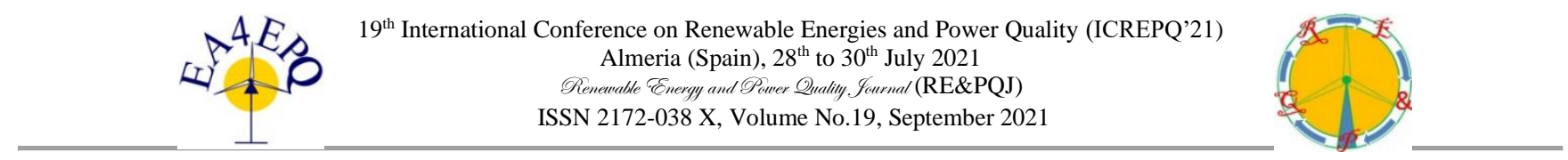

\title{
Cycle-Life Curves Determination and Modelling of Commercially Available Electric Vehicle Batteries
}

\author{
G. Saldaña ${ }^{1}$, J.I. San Martín ${ }^{2}$, F.J. Asensio ${ }^{2}$, I. Zamora ${ }^{3}$, O. Oñederra ${ }^{3}$, M. González-Pérez ${ }^{2}$ \\ and I.J. Oleagordía ${ }^{4}$
}

\author{
${ }^{1}$ Department of Systems and Automatic Engineering \\ Engineering School of Bilbao, University of the Basque Country \\ Pza. Ingeniero Torres Quevedo, 1, 48013 Bilbao (Spain)
}

Phone number: +0034 946 014310, e-mail: gaizka.saldana@ehu.eus

${ }^{2}$ Department of Electrical Engineering

Engineering School of Gipuzkoa, University of the Basque Country

Avda. Otaola, 29, 20600 Eibar (Spain)

Phone number: +0034 943 033064, e-mail: joseignacio.sanmartin@ehu.eus

\author{
${ }^{3}$ Department of Electrical Engineering \\ Engineering School of Bilbao, University of the Basque Country \\ Pza. Ingeniero Torres Quevedo, 1, 48013 Bilbao (Spain) \\ Phone number: +0034 946 014063, e-mail: inmaculada.zamora@ehu.eus \\ ${ }^{4}$ Department of Electronic Technology \\ Engineering School of Bilbao, University of the Basque Country \\ Pza. Ingeniero Torres Quevedo, 1, 48011 Bilbao (Spain) \\ Phone number: +0034 946 014304, e-mail: ii.oleagordia@ehu.eus
}

\begin{abstract}
In recent decades, there has been a growing concern about the trend of global emissions, and in particular those of the transport sector. In this context, the electric vehicle is a promising technology, with some barriers still to be overcome. Among these deficiencies everything related to storage technology is found. In this sense, lithium-ion batteries are one of the options to be considered, although it is necessary to continuously monitor the state of health. Cycle life vs DoD curves are very useful for characterizing profitability in any application that considers battery storage, as well as life cycle optimization studies. Cycle life refers to the number of charge-discharge cycles that a battery can provide before performance decreases to an extent that it cannot perform the required functions (e.g., $80 \%$ compared to a fresh one in electromobility applications). In this paper, a model for calculating the Cycle Life vs DoD curves is proposed, applied to a commercially available electric vehicle, the Renault Zoe. Modelling results show $\mathrm{R}$ squared coefficient of determinations above 0.9890 .
\end{abstract}

Key words. Battery, Degradation, Model, Li-Ion-NMC, Electric Vehicle.

\section{Introduction}

In 2019, Greenhouse Gas (GHG) emissions from fossil fuels reached 36.81 gigatons of carbon dioxide equivalent ( $\mathrm{GtCO} 2 \mathrm{e}$ ), increasing between $0.4 \%$ and $2.1 \%$ over the previous year. Moreover, it is estimated that GHG emissions will double by 2050 if actions are not taken [1,2]. The transport sector was responsible for $35 \%$ of the total energy consumed in 2014, of which $21 \%$ corresponded to passenger transport, with an average consumption of 1.9 $\mathrm{MJ} / \mathrm{pKm}$ [3]. Passenger transport by road accounted for $49.7 \%$ of total energy consumption from oil in 2015 with 1908.48 MToe and 5553.34 $\mathrm{MtCO}_{2}$ [3]. Considering all mentioned data, there is still a long way to reach the scenario of zero net emissions by 2060 from IEA [2]. In this scenario, the energy and transport sectors play a fundamental role in achieving the zero emissions goal, through the development and implementation of new technologies such as Electric Vehicles (EV) and the improvement of energy generation processes

Nowadays, electric vehicles (EVs) are booming, due to the existing environmental problems. Among the different storage technologies in electromobility, batteries stand out the most. Although there are other alternatives such as hydrogen storage, a battery is also required for DC bus voltage stabilization and switching on of other essential or auxiliary devices of the fuel cell system [4]. High capital costs, limited lifetime, and relatively poor performance at low temperatures are the most important issues in EVs [58]. Therefore, the development of efficient storage technologies is an essential part for electromobility [9].

Lithium technology is highlighted for electromobility among the studied batteries options [10]. Its specific power and energy density are the highest, with the lowest self-discharge ratio [11]. In addition, voltage by cell is 
higher, which is the major drawback of the low overcharging tolerance. Therefore, a specifically designed charging system is required for this type of battery.

Battery performance and health are also important factors from the perspective of a life cycle. Battery health has a direct impact on the maximum usable range of an $\mathrm{EV}$ and also affects its residual value because the battery is the most expensive component in it. In this context, a battery is assumed to have reached its end-of-life (EoL) when its health-accounting capacity retention falls under $80 \%$ [1]. Unfortunately, the lifetime of even state-of-the-art battery systems is considered too low, and further research is needed on this matter [2]. Therefore, increasing useful battery life and reducing the cost of the cells are determining factors in achieving a massive integration of EVs.

\section{Battery cycle aging model}

Based on the results of some experimental tests, the degradation model considered battery degradation by cycling in capacity fade terms [15]. Later, this degradation model was used to characterise the EoL of these cells, which is the aim of this paper.

The studied cell is the commercially available "Pouch" cell LG Chem E63, which was engineered for high-demanding applications and installed in Renault Zoe EVs. This highcapacity lithium-ion cell includes a nickel-manganesecobalt cathode and a graphite anode.

Testing procedure has been as follows: These cells were cycled at a specified temperature while the measurements were performed, generally in 200 cycle steps. The cells were discharged at $32.5 \mathrm{~A}$ constant current, i.e., at $\mathrm{C} / 2 \mathrm{C}$-rate, until $2.50 \mathrm{~V}$ was reached. Then, the cells were charged at constant current in two stages: the first at $21.6 \mathrm{~A}(\mathrm{C} / 3)$ and the second at $13 \mathrm{~A}(\mathrm{C} / 5)$, until $4.05 \mathrm{~V}$ and $4.20 \mathrm{~V}$ were reached, respectively. Both processes were realized at 25 ${ }^{\circ} \mathrm{C}$, with 60 minutes resting time between them.

In the development of the model, the following assumptions were made:

- Battery degradation can be classified as cycling aging and calendar aging. These phenomena can be decoupled.

- $\mathrm{DoD}=0$ and/or $\mathrm{C}=0$ cycles produce no degradation by cycling aging, as in these conditions, there is no cycling and all degradation produced can be assumed to be calendar aging.

- As this model is based on interpolations, the highest confidence bounds are defined by the available data, as shown in Table 1. However, using this model to calculate battery degradation out of these confidence bounds is also possible.

Table I. - Confidence bounds for cycle aging.

\begin{tabular}{|c|c|c|c|}
\hline Temperature $(\mathrm{T})$ & DoD & FEC & C-Rate \\
\hline$[25-45]^{\circ} \mathrm{C}$ & {$[20-80] \%$} & $\begin{array}{c}{[0-1800]} \\
\text { cycles }\end{array}$ & $\begin{array}{c}{[0.3786-} \\
0.6710] \mathrm{C}\end{array}$ \\
\hline
\end{tabular}

After collecting all experimental test results, data treatment and normalization were undertaken to get a normalized data matrix comprising all possibilities. Although the experimental tests were realized at concrete values of $\mathrm{DoD}$, temperature, and C-rate, the developed model can obtain degradation values using any value of these factors. For every test performed, an equation describing degradation was determined considering every DoD, N, T, and C, following (1).

$$
S o H_{C}=100-a_{C} \cdot(D o D, C . T) \cdot N^{b_{C}(C, T)}
$$

where $\mathrm{SoH}_{\mathrm{C}}$ is the state of health, $\mathrm{a}_{\mathrm{C}}$ is a prepotential factor, $\mathrm{N}$ is the number of full equivalent cycles [FEC], and $b_{C}$ is a potential factor that better fits available data.

For every data set, a linear regression adjustment was calculated, considering the following:

- All data sets were adjusted to (11) or (12).

- All data sets for the same temperature and C-rate were normalized using nonlinear square regressions of multiple data sets, and the $b$ factor was set to a constant along DoD in order to obtain non-crossed curves. Consequently, $a$ factor varies along operating DoD, $\mathrm{T}$, and $\mathrm{C}$, while the $b$ factor varies along operating $\mathrm{T}$ and $\mathrm{C}$.

The degradation model results and validation are shown in Figure 1, where it can be seen the simulated surface and measured experimental values. The maximum error when simulating $\mathrm{CF}$ was $3.74 \%$, given when $\mathrm{DoD}=0.8, \mathrm{~N}=100$ cycles, $\mathrm{T}=45^{\circ} \mathrm{C}, \mathrm{C}=0.3786$, while average RMSE was $1.12 \%$.

\section{Cycle-Life vs DoD}

The model explained in the previous section has been evaluated along different DoDs, temperatures and currents, in search of the number of FECs necessary in each condition to reach an EoL of $80 \%$. If said number of cycles is plotted as a function of the cycling DoD, the socalled Cycle-Life vs DoD curve is obtained, which is especially useful for evaluating different situations under identical energetic conditions. It has been experimentally determined that these curves follow the equation defined in (2):

$$
C L[F E C]=a(C, T) \cdot D o D^{b(C, T)}+c(C, T)
$$

where CL is the Cycle-Life [-], $a$ is a prepotential coefficient, $b$ is a potential coefficient [-], $c$ is an offset coefficient [-] and DoD is the depth of discharge [-].

Knowing the CL in terms of FEC, it is possible to calculate the number of cycles at a certain DoD, according to expression (3).

$$
C L[N @ D o D]=\frac{C L[F E C]}{D o D}
$$

where CL is the Cycle-Life expressed in number of cycles at a certain DoD and DoD the depth of discharge [-]. 

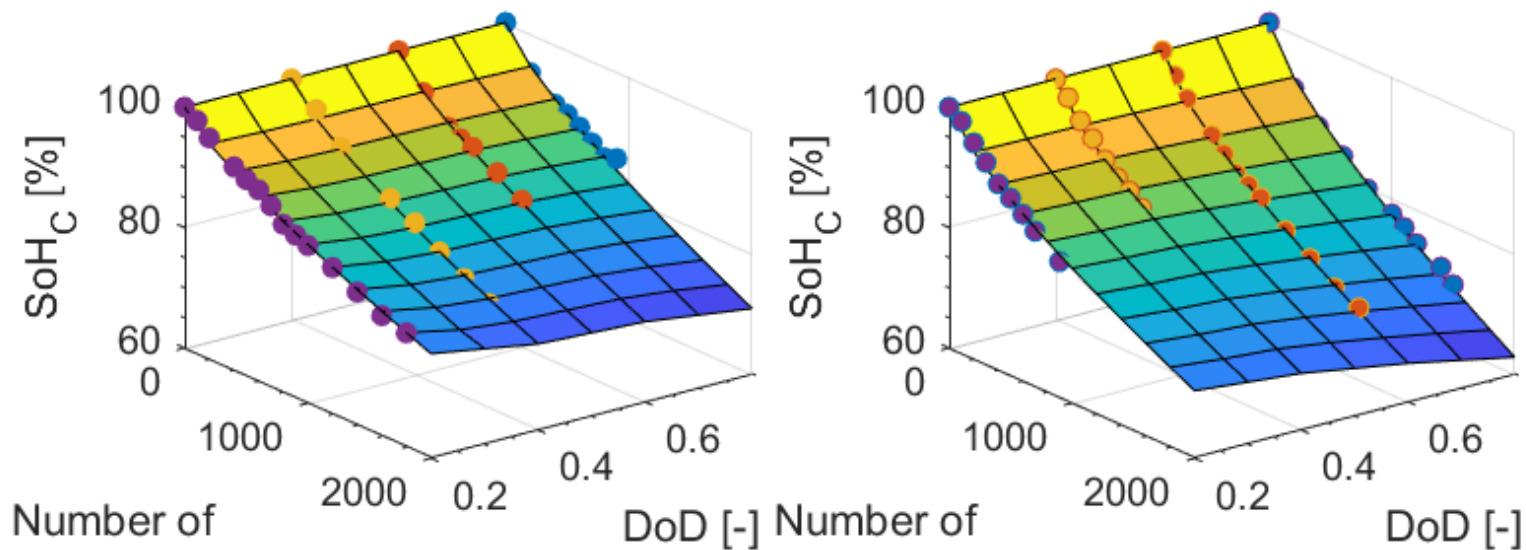
cycles [-]

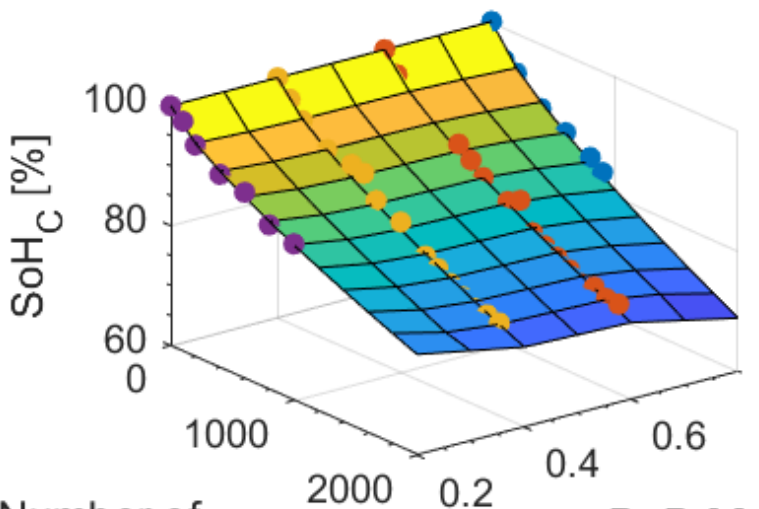

cycles [-]
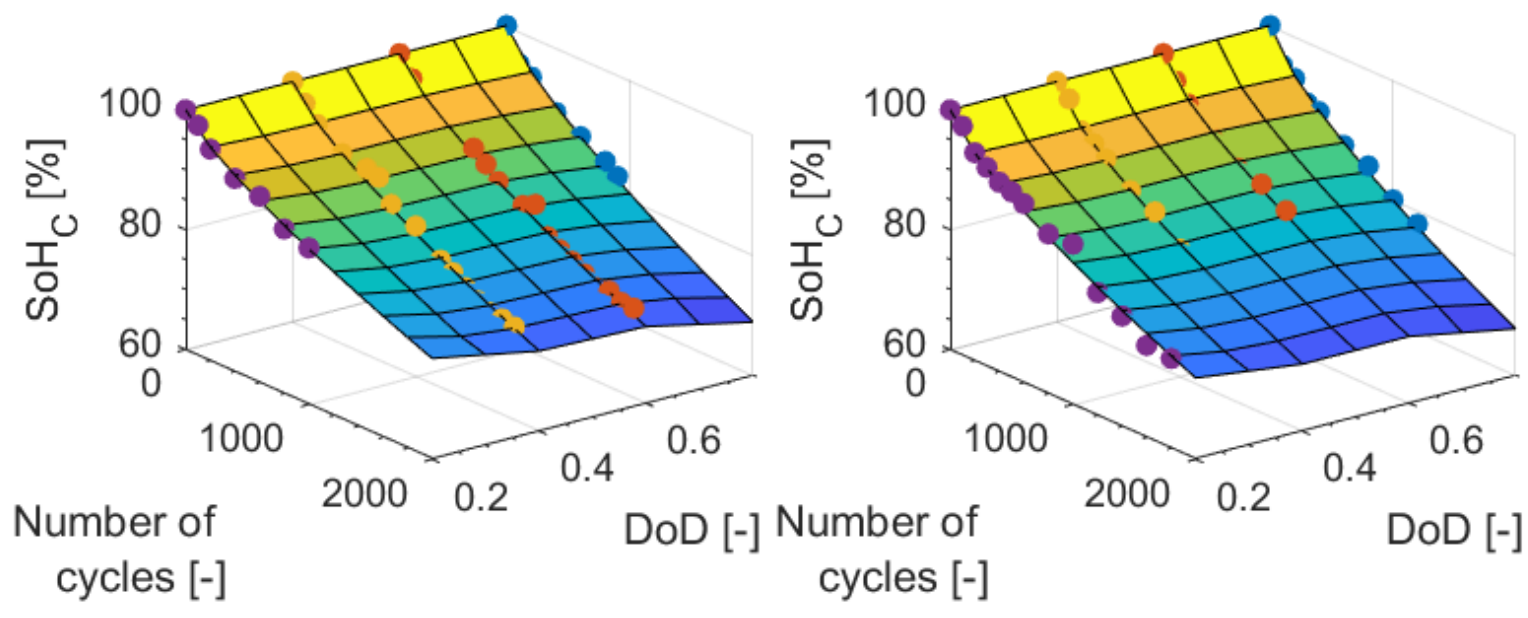

Fig. 1. Capacity degradation for a) $25 \mathrm{C} 0.3786 \mathrm{C}$, b) $45 \mathrm{C} 0.3786 \mathrm{C}$ c) $25 \mathrm{C} 0.4812 \mathrm{C} \mathrm{d}) 25 \mathrm{C} 0.6710 \mathrm{C}$.

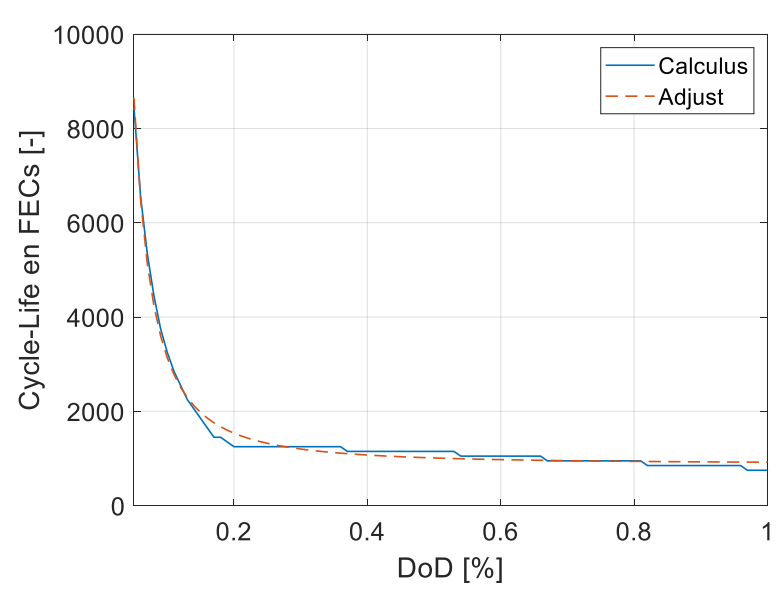

a)

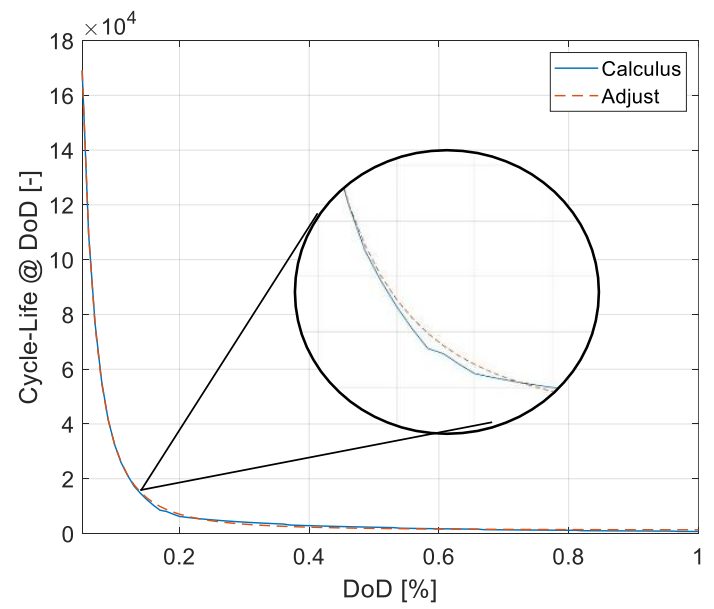

b)

Fig. 2. Cycle-Life, as a function of the DoD at $45^{\circ} \mathrm{C}$ and C-Rate $=0.4 \mathrm{C}$, a) expressed in FECs and b) expressed in number of cycles@DoD.

After having calculated all cycle-life data, a model which represents cycle-life according DoD has been developed.

The model has been observed to adjust another potential law, which is expressed according to (4), and parameters values are provided in Table II.

$$
\begin{gathered}
C L[N @ D o D]=a(C, T) \cdot D o D^{b(C, T)} \\
+c(C, T)
\end{gathered}
$$

where CL is the Cycle-Life expressed in number of cycles at a certain DoD and DoD the depth of discharge [-]. 


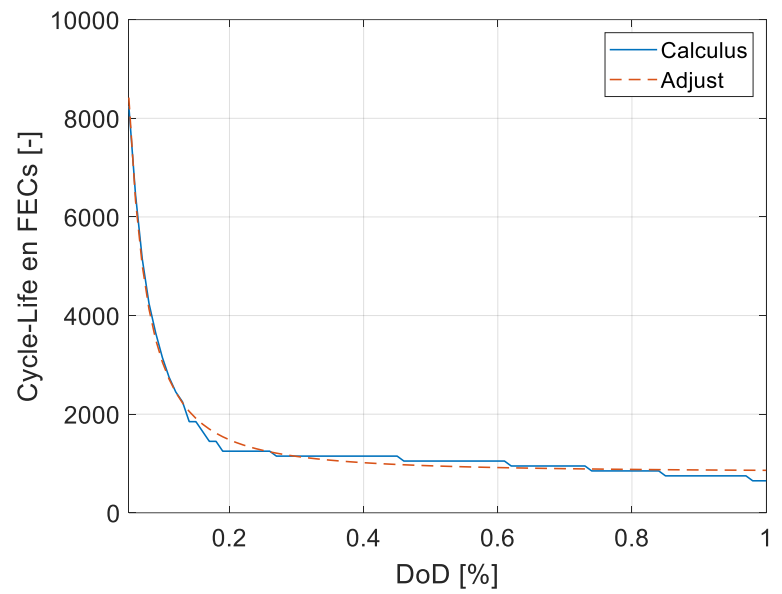

a)

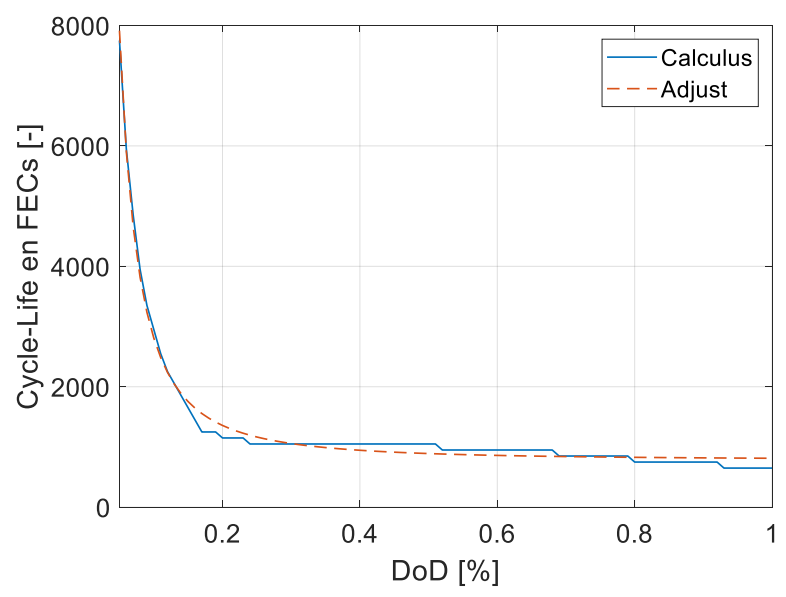

c)

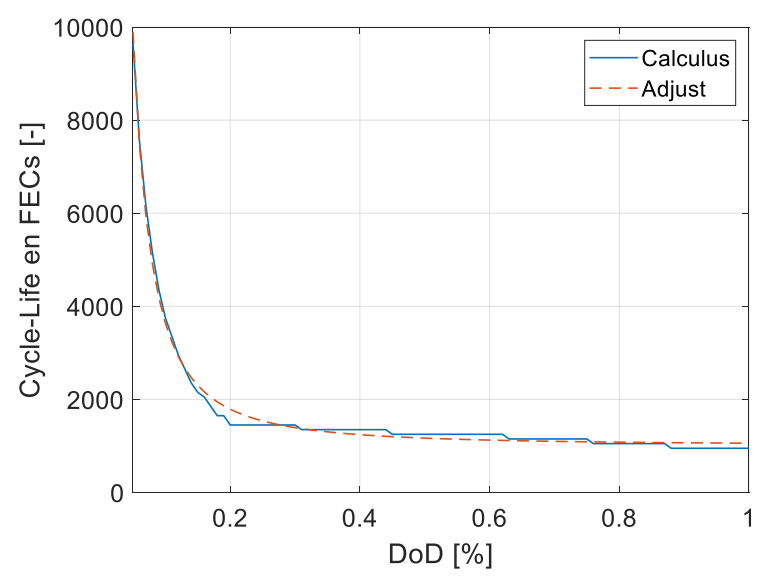

e)

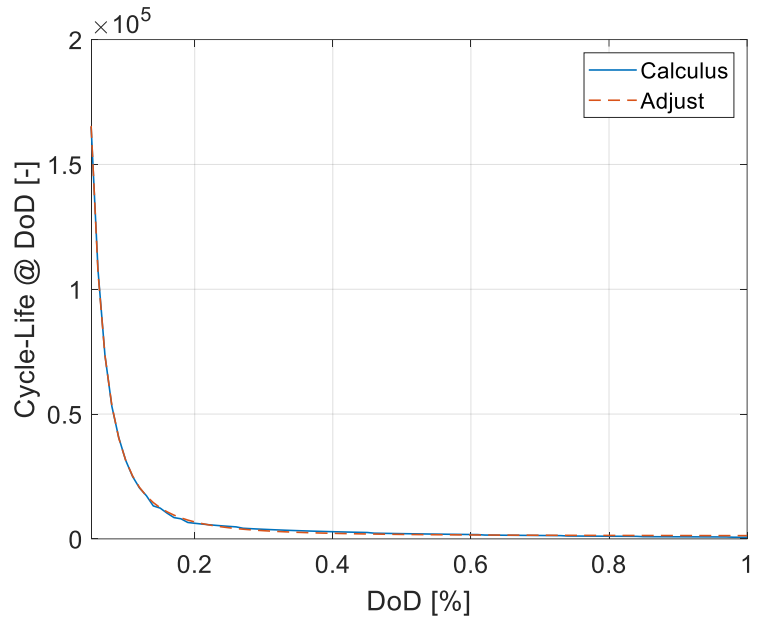

b)

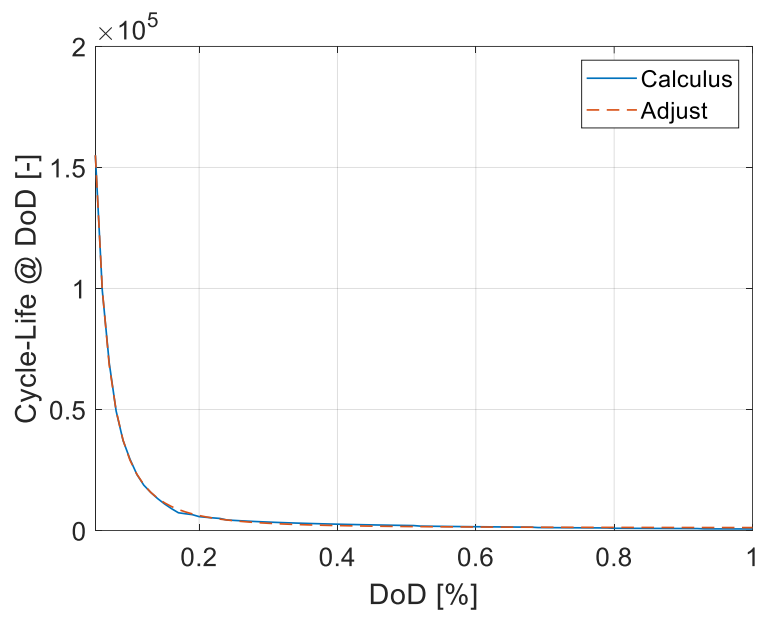

d)

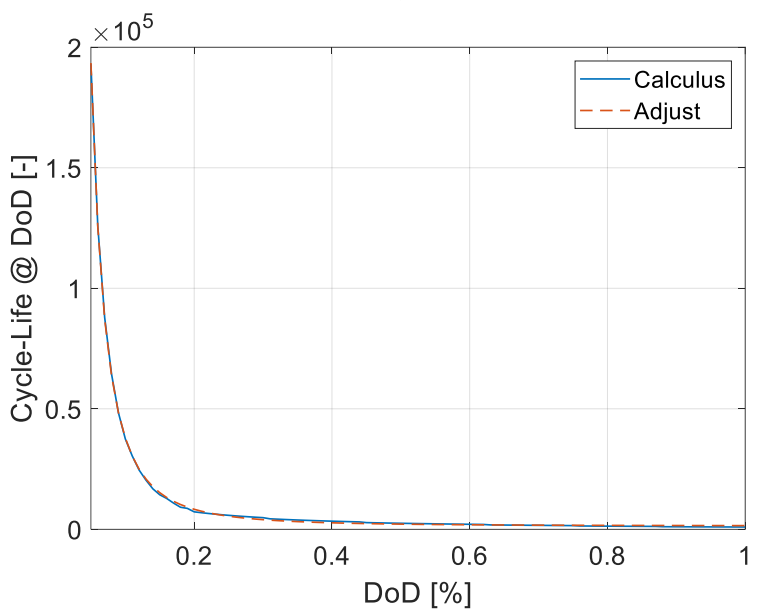

f)

Fig. 3. Cycle-Life adjusts studied, a) $45^{\circ} \mathrm{C}$ and $\mathrm{C}$-Rate $=0.5 \mathrm{C}$ expressed in FECs, b) $45^{\circ} \mathrm{C}$ and $\mathrm{C}$-Rate $=0.5 \mathrm{C}$ expressed in number of cycles @ DoD, c) $45^{\circ} \mathrm{C}$ and C-Rate $=0.6 \mathrm{C}$ expressed in FECs, d) $45^{\circ} \mathrm{C}$ and $\mathrm{C}$-Rate $=0.6 \mathrm{C}$ expressed in number of cycles @ DoD, e) $35^{\circ} \mathrm{C}$ and C-Rate $=0.4 \mathrm{C}$ expressed in FECs and f) $35^{\circ} \mathrm{C}$ and $\mathrm{C}$-Rate $=0.4 \mathrm{C}$ expressed in number of cycles @ DoD.

Table II. Data of the adjustments performed and correlation coefficients.

\begin{tabular}{|c|c|c|c|c|c|c|c|c|c|}
\hline \multirow{2}{*}{$\mathbf{C}_{\text {Carga }}$} & \multirow{2}{*}{$\mathbf{T}$} & \multicolumn{4}{|c|}{ FEC } & \multicolumn{3}{c|}{ N @ DoD } \\
\cline { 3 - 10 } & & $\boldsymbol{a}$ & $\boldsymbol{b}$ & $\boldsymbol{c}$ & $\mathbf{R}^{\mathbf{2}}$ & $\boldsymbol{a}$ & $\boldsymbol{b}$ & $\boldsymbol{c}$ & $\mathbf{R}^{\mathbf{2}}$ \\
\hline \multirow{3}{*}{$0,4 \mathrm{C}$} & $25^{\circ} \mathrm{C}$ & 55,18 & $-1,749$ & 1175 & 0,9934 & 178,6 & $-2,382$ & 1559 & 0,9997 \\
\cline { 2 - 10 } & $35^{\circ} \mathrm{C}$ & 45,82 & $-1,758$ & 1012 & 0,9925 & 146,2 & $-2,397$ & 1384 & 0,9996 \\
\cline { 2 - 10 } & $45^{\circ} \mathrm{C}$ & 36,88 & 1,786 & 883,4 & 0,9904 & 117,9 & $-2,424$ & 1242 & 0,9995 \\
\hline $0,5 \mathrm{C}$ & $45^{\circ} \mathrm{C}$ & 38,26 & $-1,766$ & 823,2 & 0,9900 & 110,6 & $-2,438$ & 1190 & 0,9995 \\
\hline $0,6 \mathrm{C}$ & $45^{\circ} \mathrm{C}$ & 31,03 & $-1,815$ & 781,3 & 0,9890 & 96,8 & $-2,461$ & 1125 & 0,9996 \\
\hline
\end{tabular}




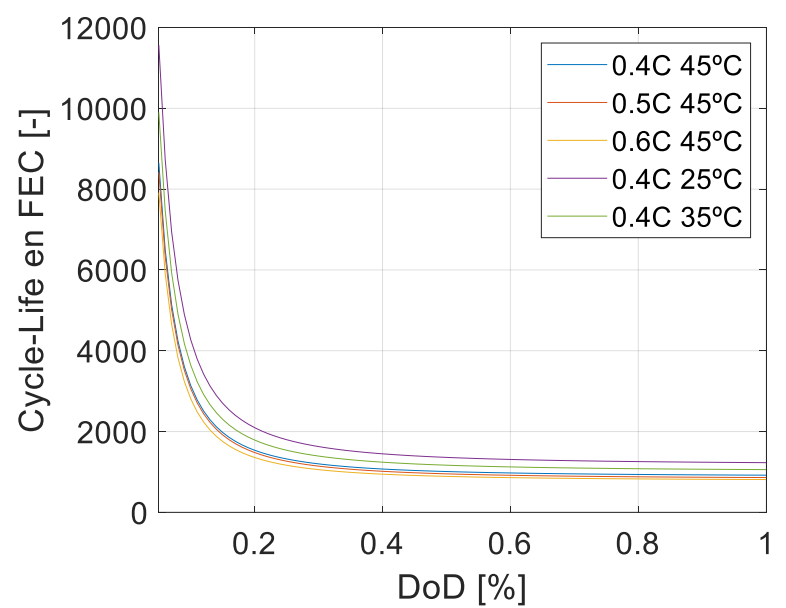

a)

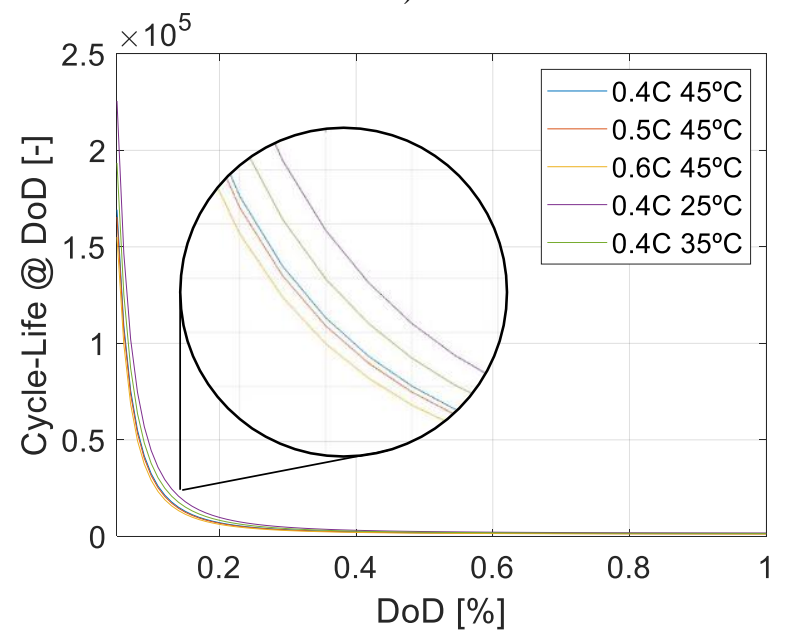

b)

Fig. 4. Cycle-Life adjusts studied, a) expressed in FECs and b) expressed in number of cycles @ DoD.

Figure 2 shows this adjustment for the case of $45^{\circ} \mathrm{C}$ and $\mathrm{C}$ $=0.4 \mathrm{C}$, where the influence of the DoD on the CL can be appreciated. The adjustments for the rest of the cases studied are included in Figure 3. Note the difference between FEC and cycle @ DoD, the CL being expressed in FEC and in number of cycles at certain DoD, respectively. It is observed that very shallow cycling is highly beneficial in terms of cycling degradation.

However, the minimum DoD will be determined by the range need of the EV user, while the total useful life will also be influenced by degradation due to calendar aging, among others. Table II shows the adjustments and correlations for the different cases studied, while these cases are graphed in Figure 4.

In provided Table II, it can be seen that the model fits very well to data in $\mathrm{N} @$ DoD terms, given by a minimum $\mathrm{R}^{2}$ correlating factor of 0.9995 . Furthermore, it is observed how the cycling temperature is a key variable in the useful life of a battery, comparable to the working current-rate. In this context, under operating conditions of $\mathrm{DoD}=40 \%, \mathrm{C}$ Rate $=0.4 \mathrm{C}$ and $\mathrm{T}=45^{\circ} \mathrm{C}$, studied cells last 2328 cycles, or 1072 FEC; under $\mathrm{C}$-Rate $=0.6 \mathrm{C}$ and $\mathrm{T}=45^{\circ} \mathrm{C}$, studied cells last 2048 cycles, or 945 FEC; while under C-Rate $=0.4 \mathrm{C}$ and $\mathrm{T}=25^{\circ} \mathrm{C}$, studied cells last 3142 cycles, or 1448 FEC.
Although measuring cycle-life in FEC is very useful for accounting for total energy throughput or kilometres driven, number of cycles at certain DoD (N @ DoD) has to be checked as well, as it defines the maximum number of trips before cells reaching their end-of-life in that application, for example.

\section{Conclusion}

Battery degradation is one of the main problems of energy storage, in automotive applications as well as in stationary applications. Knowing the rate of degradation of a battery under a known working cycle is necessary for technology general deployment and performance improvement, as well as life cycle assessment since the usage optimization improves life cycle. Therefore, research on how to maximize batteries' lifetime is being encouraged. Concerning electric vehicles, people do want to know, as accurately as possible, how often they will need to replace the batteries installed in their vehicles. For this purpose, it is necessary to directly monitor, or indirectly estimate, the state of health.

In this context, with the aid of this paper, and the lifetime model here presented, the trade-off between working current and temperature in batteries applications can be correctly assessed.

\section{Acknowledgement}

The authors acknowledge the support of the Basque Government (GISEL Research Group) under Grant IT1191-19 and Grant PIBA_2019_1_0098, as well as the University of the Basque Country UPV/EHU under Grant COLAB19 and PES16/31.

\section{References}

[1] Global Carbon Project 2018. Analysis: Global CO2 Emissions Set to Rise 2\% in 2017 after Three-Year 'Plateau'. Available online: https://www.carbonbrief.org/analysis-global-co2emissions-set-to-rise-2-percent-in-2017-following-threeyear-plateau (accessed on 18 August 2018).

[2] IEA. Energy Technology Perspectives 2017: Catalysing Energy Technology Transformations; IEA: Paris, France, 2017. 3.

[3] OECD Publishing. World Energy Statistics 2017; IEA: Paris, France, 2017.

[4] Zamora, I.; San Martín, J.I.; García, J.; Asensio, F.J.; Oñederra, O.; San Martín, J.J.; Aperribay, V. PEM fuel cells in applications of urban public transport. Renew. Energy Power Qual. J. 2011, 1, 599-604.

[5] Yan, J.; Li, C.; Xu, G.; Xu, Y. A novel on-line self-learning state-of-charge estimation of battery management system for hybrid electric vehicle. In Proceedings of the 2009 IEEE Intelligent Vehicles Symposium (IVS), Xi'an China, 3-5 June 2009; pp. 1161-1166.

[6] Shen, J.; Dusmez, S.; Khaligh, A. An advanced electrothermal cycle-lifetime estimation model for LiFePO4 batteries. In Proceedings of the 2013 IEEE Transportation Electrification Conference and Expo (ITEC), Detroit, MI, USA, 16-19 June 2013; pp. 1-6. 
[7] Eddahech, A.; Briat, O.; Vinassa, J. Real-Time SOC and $\mathrm{SOH}$ Estimation for $\mathrm{EV}$ Li-Ion Cell Using Online Parameters Identification. In Proceedings of the 2012 IEEE Energy Conversion Congress and Exposition, Raleigh, NC, USA, 15-20 September 2012.

[8] Hentunen, A.; Lehmuspelto, T.; Suomela, J. Electrical battery model for dynamic simulations of hybrid electric vehicles. In Proceedings of the 2011 IEEE Vehicle Power and Propulsion Conference (VPPC), Chicago, IL, USA, 6-9 September 2011; pp. 1-6.

[9] Lombardi, L.; Tribioli, L.; Cozzolino, R.; Bella, G. Comparative environmental assessment of conventional, electric, hybrid, and fuel cell powertrains based on LCA. Int. J. Life Cycle Assess. 2017, 22, 1989-2006.

[10] Thomas, C.E. Fuel cell and battery electric vehicles compared. Int. J. Hydrogy Energy 2009, 34, 6005-6020.

[11] Hu, X.; Zou, C.; Zhang, C.; Li, Y. Technological Developments in Batteries: A Survey of Principal Roles,

Types, and Management Needs. IEEE Power Energy Mag. 2017, $15,20-31$.

[12] A. W. Thompson, "Economic implications of lithium ion battery degradation for vehicle-to-grid (V2X) services," J. Power Sources, vol. 396, pp. 691-709, Aug. 2018.

[13] B. Weiÿhar and W. G. Bessler, "Model-based lifetime prediction of an LFP/graphite lithium-ion battery in a stationary photovoltaic battery system,"J. Energy Storage, vol. 14, pp. 179-191, Dec. 2017.

[14] "Rechargeable lithium ion battery E63" LG Chem, Seoul, South Korea, Tech. Rep., Feb. 2018.

[15] G. Saldaña, J. I. San Martín, I. Zamora, F. J. Asensio, O. Oñederra and M. González, "Empirical Electrical and Degradation Model for Electric Vehicle Batteries," in IEEE Access, vol. 8, pp. 155576-155589, 2020. 